\title{
Targeting Transcriptional and Epigenetic Reprogramming in Stromal Cells in Fibrosis and Cancer
}

\author{
Nasun Hah, ${ }^{1,3}$ Mara H. Sherman, ${ }^{1,3}$ Ruth T. Yu, ${ }^{1}$ Michael Downes, ${ }^{1}$ \\ AND Ronald M. Evans ${ }^{1,2}$ \\ ${ }^{1}$ Gene Expression Laboratory, The Salk Institute for Biological Studies, La Jolla, \\ California 92037 \\ ${ }^{2}$ Howard Hughes Medical Institute, The Salk Institute for Biological Studies, La Jolla, \\ California 92037 \\ Correspondence: evans@salk.edu
}

\begin{abstract}
The basis of many human diseases arises from both genetic and epigenetic regulation. Recent advances in the understanding of the mechanisms underlying transcriptional and epigenetic regulation and their prevalence as contributors to a diverse range of human diseases have led us to focus on transcription and epigenetic changes in a variety of human disease conditions. Specifically, our recent studies in liver fibrosis and pancreatic cancer have demonstrated that the epigenetic regulation in hepatic stellate cells (HSCs) and pancreatic stellate cells (PSCs) significantly contributes to the progress in such diseases and presents great therapeutic potential. We show that the vitamin D receptor (VDR) acts as a master genomic suppressor in both HSC and PSC activation. The studies also have demonstrated that the VDR ligand reduces fibrosis and inflammation in a murine liver fibrosis and pancreatitis model. Although our current studies focus on characterizing the roles of VDR and regulatory regions within gene promoters and regulatory enhancers, we have expanded our effort to epigenetic mechanisms as major determinants of gene activation and repression in order to develop potential therapeutics to modulate stroma-associated pathologies including inflammation, fibrosis, and cancer.
\end{abstract}

Regulation of gene expression is a critical step in establishing and maintaining specific cell states that is carried out through highly conserved processes that contribute to normal development and adaptation to changes in cellular and tissue homeostasis (Lee and Young 2013). This process is precisely regulated by transcription factors and cofactors as well as chromatin and epigenetic regulators. Thus, the main focus of studying transcriptional and epigenetic changes has been to understand the fundamental mechanisms of how chromatin plays a critical role in regulation of gene expression. Recent advances in the understanding of the mechanisms underlying transcriptional modulation and their prevalence as contributors to a diverse range of human diseases have led us to focus on epigenetic changes in a variety of human disease conditions. Thus any diseases that alter the cellular milieu to the point of triggering adaptive changes in phenotype will likely involve one or more epigenetic mechanisms.

Stellate cells were first discovered as vitamin A-storing cells in a variety of tissues including liver and pancreas (Wake 1971; Watari et al. 1982). Hepatic stellate cells (HSCs) have been the most intensively studied among these different types of stellate cells. In normal tissue, HSCs maintain a quiescent state, and comprise 5\%-8\% of the total number of liver cells (Friedman 2000). HSCs contain lipid droplets in their cell bodies, storing vitamin A mainly as a form of retinyl palmitate (Friedman 2000). The function and role of quiescent HSCs remain unclear; however, a recent study suggested that HSCs act as liver- resident antigen-presenting cells, presenting lipid antigens to and stimulating proliferation of a subset of immune cells (Abramovitch et al. 2011). HSCs have also been thought to maintain tissue homeostasis by regulating extracellular matrix turnover (Breitkopf et al. 2006; Inagaki and Okazaki 2007). Interestingly, many studies have shown that liver damage triggers these quiescent HSCs to an activated state, where the cells undergo drastic changes in their proliferation, contractility, chemotaxis, and the amount of vitamin A stored in their lipid droplets (Friedman 2008). Quiescent HSCs transdifferentiate into wound-healing myofibroblasts and acquire potent proinflammatory and profibrogenic activities (Bataller and Brenner 2005; Hernandez-Gea and Friedman 2011). As the liver damage progresses, stellate cells secrete collagen, resulting in fibrosis, which, in turn, leads to liver cirrhosis. Pancreatic stellate cells (PSCs) were first isolated from rats fed with a vitamin A-rich diet (Apte et al. 1998; Bachem et al. 1998), are found in a quiescent state in healthy tissue, and are believed to play roles in tissue homeostasis (Riopel et al. 2013). Similar to HSCs, quiescent PSCs are characterized in part by cytoplasmic lipid droplets rich in vitamin A (Apte et al. 1998; Bachem et al. 1998). The importance of PSCs as key contributors to the stromal reaction in pancreatic ductal adenocarcinoma has been emphasized (Vonlaufen et al. 2008). PSCs also become activated and transdifferentiate into myofibroblast-like cells upon tissue damage or pancreatic tumorigenesis (Wehr et al. 2011).

\footnotetext{
${ }^{3}$ These authors contributed equally to this work.

Copyright (C) 2015 Cold Spring Harbor Laboratory Press; all rights reserved; doi: 10.1101/sqb.2015.80.027185 
It is apparent that these stromal cells play a crucial role in normal and pathophysiological conditions. The characterization of these activated hepatic and pancreatic stellate cells during liver and pancreatic tissue injury as well as tumorigenesis has led to intense investigation into the transcriptional regulatory network underlying stellate cell states. Although the current studies in our laboratory focus on characterizing interactions between transcription factors such as nuclear receptors and regulatory regions within gene promoters and regulatory enhancers, we have extended our investigation to include epigenetic mechanisms as major determinants of gene activation and repression - in particular, histone acetylation.

\section{TARGETING LIVER FIBROSIS AND EPIGENETIC REPROGRAMMING IN STELLATE CELLS}

Hepatic fibrosis is defined by the excessive accumulation of extracellular matrix (ECM) and loss of liver function in most types of chronic liver diseases (Bataller and Brenner 2005; Hernandez-Gea and Friedman 2011). Because HSCs have been identified and characterized as key players in depositing ECM in normal and fibrotic liver, a variety of approaches have been intensely explored to develop therapeutics to reverse and prevent this pathological process. Nonetheless, it remains unclear how transcriptional and epigenetic reprogramming is precisely regulated during the dramatic transformation from quiescent HSCs to activated wound-healing myofibroblasts. It also remains to be elucidated how activated HSCs acquire the ability to respond to the microenvironment to secrete profibrogenic, proinflammatory molecules and change proliferative capacity and contractility. A plethora of studies have revealed that a diverse set of transcription factors are involved stellate cell biology including SMADs, NF-кB, CREB, MyoD, Ets, AP-1, RUNX, C/EBP, and nuclear hormone receptors (Mann and Mann 2009). These advances in our understanding of transcriptional regulation in stromal cells such as HSCs in liver fibrosis led us to further explore antifibrotic drugs that target the transcriptional regulators. In this review, we focus on a member of the nuclear hormone receptor (NHR) superfamily, vitamin D receptor (VDR). Interestingly, the closest structural and functional relatives of VDR within the NHR superfamily include farnesoid $\mathrm{X}$ receptor (FXR), constitutive androstane receptor (CAR), and pregnane $\mathrm{X}$ receptor (PXR), all of which are regulators of bile acid homeostasis and xenobiotic detoxification in the liver (Bookout et al. 2006; Bouillon et al. 2008). However, because of low levels of VDR expression in liver, the physiological importance of vitamin $D$ in hepatic function has long been overlooked (Bookout et al. 2006; Han et al. 2010). Nonetheless, the finding of robust VDR expression in HSCs led us to consider it as a possible modulator of liver fibrosis (Gascon-Barré et al. 2003). Recent studies have shown that the active form of vitamin $\mathrm{D}$ has antiproliferative and antifibrotic effects on liver fibrosis in in vitro and in vivo models (Abramovitch et al. 2011). In our study, we found that VDR ligands inhibit HSC activation by TGF $\beta 1$, which has been implicated in liver fibrosis (Inagaki and Okazaki 2007; Ding et al. 2013). Interestingly, Vdr knockout mice spontaneously develop hepatic fibrosis, indicating that VDR plays a critical role in normal liver homeostasis (Ding et al. 2013). To further understand how VDR can regulate liver fibrosis and HSC activation, we used a genome-wide approach to map VDR-binding sites (VDR cistrome) in HSCs. We found that TGF $\beta 1$ signaling causes a redistribution of VDR binding genome-wide and facilitates VDR binding at SMAD3, a downstream effector of TGF $\beta 1$, and other profibrotic target genes via TGF $\beta 1$ dependent chromatin remodeling (Ding et al. 2013). In the presence of VDR ligands, VDR binding to the coregulated genes reduces SMAD3 occupancy at these sites, resulting in inhibition of fibrosis. These results reveal that the interplay between VDR and SMAD regulates hepatic fibrogenesis and defines a role for VDR as an endocrine checkpoint to modulate the wound-healing response in liver (Fig. 1). Furthermore, the findings suggest VDR ligands as a potential therapy for liver fibrosis.

Subsequently, this work led us to explore the epigenetic changes between HSC activation and quiescence. Screens exploring epigenetic regulators identified BRD4, a member of the BET (bromodomain and extra terminal domain) family, as a potent driver of the fibrotic response (Ding et al. 2015). The enrichment of BRD4 binding at the distal enhancer of profibrotic genes provides novel mechanistic insight into the injury response. Indeed, the remarkable efficacy of the BRD4 inhibitor JQ1 in preventing liver injury and reversing or limiting the progression of existing fibrosis is, in part, due to the enhanced sensitivity of BRD4-enhancer association to pharmacological intervention (Fig. 1; Filippakopoulos et al. 2010).

In summary, our studies identified intrinsic genomic and epigenetic mechanisms that can be exploited pharmaceutically to ameliorate liver fibrosis. These ubiquitously expressed transcription factors and epigenetic

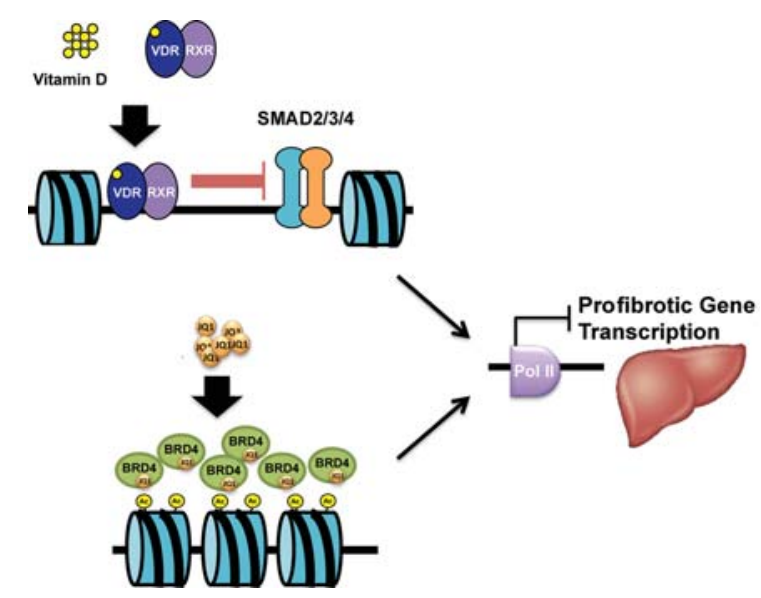

Figure 1. Model depicting proposed transcriptional and epigenetic control of liver fibrogenesis either by the vitamin $D$ receptor (VDR) targeting a TGF- $\beta /$ SMAD pathway or by a BET inhibitor (JQ1) targeting BET family proteins. 
regulators are likely to be applicable to many other cell types and may impact the pathogenesis of a wide range of human diseases.

\section{TRANSCRIPTIONAL AND EPIGENETIC REGULATION OF THE PANCREATIC TUMOR MICROENVIRONMENT}

Our interest in stellate cells led us to investigate the stromal reaction associated with pancreatic cancer. Pancreatic ductal adenocarcinoma (PDAC) is the most common form of pancreatic cancer and has the worst 5-yr survival rate $(\sim 6 \%)$ of any cancer. The near-uniform lethality of pancreatic cancer results in part from the lack of effective early detection strategies, typically advanced disease state at diagnosis, and resistance to established therapeutic regimens. Although early detection remains a crucial goal in pancreatic cancer research and promising inroads have recently been made in this area (Melo et al. 2015), the need to improve therapeutic efficacy for patients diagnosed with advanced disease prompted us to address mechanisms of therapeutic resistance in PDAC. As in other solid tumor types (Klemm and Joyce 2015), the tumor microenvironment of PDAC has been implicated as a barrier to therapeutic efficacy. Genetically engineered mouse models (GEMMs) that faithfully recapitulate human PDAC have been instrumental in the identification of physical and biochemical microenvironmental properties that promote therapeutic resistance. Although the "KPC" GEMM of PDAC (Hingorani et al. 2005) is resistant to the current chemotherapeutic standard of care, gemcitabine, subcutaneously transplanted tumor cells from these mice are responsive to gemcitabine treatment (Olive et al. 2009), suggesting that it is the pancreatic tumor microenvironment that is resistant to chemotherapy. Further work in this model has demonstrated that the dense ECM associated with PDAC physically impedes the intratumoral vasculature and blocks chemotherapy delivery, which can be dramatically restored by enzymatic depletion of a key ECM component (Provenzano et al. 2012; Jacobetz et al. 2013). In light of these studies, we reasoned that an improved understanding of the molecular basis of tumor-stroma interactions in PDAC may identify potential targets for therapeutic intervention.

PSCs are key contributors to the stromal reaction in PDAC (Vonlaufen et al. 2008). Similar to the closely related HSCs (Buchholz et al. 2005), PSCs are found in a quiescent state in healthy tissue, and quiescent PSCs play roles in tissue homeostasis including normal ECM turnover and maintenance of the basement membrane (Riopel et al. 2013). Quiescent PSCs are characterized in part by cytoplasmic lipid droplets rich in vitamin A (Apte et al. 1998; Bachem et al. 1998) and expression of genes associated with lipid storage including PPARG and FABP4 (Sherman et al. 2014). In the context of tissue damage or during pancreatic tumorigenesis, PSCs become activated and transdifferentiate to myofibroblastlike cells with a diverse secretome including proteins implicated in wound healing, proliferation, and fibrosis
(Wehr et al. 2011). PSCs shed their lipid droplets upon activation and undergo transcriptional changes consistent with loss of lipid storage capacity and acquisition of fibroinflammatory function (Sherman et al. 2014). Presumed tumor-supportive features of PSCs - including robust ECM production, paracrine $\mathrm{Wnt} / \beta$-catenin signaling (Froeling et al. 2011), and suppression of intratumoral T-cell infiltration (Ene-Obong et al. 2013)appear mainly associated with the activated, not quiescent, PSC phenotype. As such, we hypothesized that reverting or reprogramming activated, PDAC-associated PSCs toward quiescence would represent a viable therapeutic strategy in combination with agents targeting the neoplastic compartment. Lineage tracing studies in the context of liver injury demonstrated that this reversion of activated stellate cells to quiescence indeed occurs in vivo in HSCs, but the molecular mediators of this reverseactivation process were unknown.

To find candidate regulators of the PSC activation state, we turned to the nuclear receptor superfamily. Nuclear receptors are generally signal-dependent transcription factors that are activated by lipophilic ligands comprised of hormones, fat-soluble vitamins, and dietary lipids and subsequently induce tissue-specific transcriptional changes (Mangelsdorf et al. 1995). As a family, nuclear receptors play functional roles in target tissues, which reflect the chemical basis of ligand activation (i.e., fatty acid-regulated nuclear receptors regulate fatty acid metabolism; bile acid-regulated nuclear receptors regulate bile acid homeostasis) (Evans and Mangelsdorf 2014). The nuclear receptor superfamily therefore represents a unifying mechanism linking environmental signals with coordinate regulation of gene expression and physiological or homeostatic control. As nuclear receptors are broadly implicated in lipid metabolism, lipid storage, and negative regulation of inflammation, we reasoned that nuclear receptors and their ligands may function in homeostatic control of stellate cell activation. A screen of nuclear receptor agonists and antagonists (MH Sherman, unpubl. data) identified the VDR and synthetic vitamin $\mathrm{D}$ analog calcipotriol as negative regulators of the PSC activation program (Sherman et al. 2014). Key features of PSC activation are also negatively regulated by 1,25-dihydroxyvitamin $\mathrm{D}_{3}$ (Bläuer et al. 2015), the natural ligand for VDR. Interestingly, ligands for the retinoic acid receptor (RAR), another nuclear receptor family member, also induce transcriptional changes associated with PSC quiescence (Froeling et al. 2011), and storage of fat-soluble vitamin A, a precursor of the active ligand of RAR, in lipid droplets is a hallmark of quiescent PSCs. Whether PSC lipid droplets store fat-soluble vitamin D as well remains to be determined, but current literature implicates nuclear receptors as a molecular link between the quiescent PSC phenotype - fat and fat-soluble vitamin storage - and maintenance of a quiescence-associated transcriptional program.

We recently showed that VDR-mediated stromal reprogramming broadly suppresses a transcriptional program associated with PSC activation in PDAC stroma, including growth factors, proinflammatory cytokines, ECM 
components, and negative regulators of angiogenesis (Sherman et al. 2014). We speculate that this stromal reprogramming approach may be beneficial not only by negatively regulating tumor-supportive functions of activated PSCs but also by reprising features of quiescent PSCs associated with homeostatic control in normal tissue (Fig. 2). Future studies will aim to determine whether quiescent or reprogrammed PSCs indeed possess tumorsuppressive capacity and, if so, what molecular mediators promote pancreatic homeostasis and oppose tumor progression. Importantly, in KPC mice, calcipotriol plus gemcitabine reduced tumor growth and significantly prolonged survival compared to treatment with gemcitabine alone. Calcipotriol treatment significantly increased intratumoral concentrations of the active metabolite of gemcitabine, together with significantly increased apoptosis among tumor cells. These results suggest stromal reprogramming as a viable therapeutic approach together with chemotherapy, and future studies will aim to identify additional molecular mediators of PSC quiescence and homeostatic control.

These studies led us to question how diverse PSCderived cues, including soluble and insoluble secreted factors, influence the epithelial compartment in the pancreatic tumor microenvironment. Using a novel 3D culture system incorporating relevant secreted factors from PDAC-associated PSCs, we have found that stromal signals regulate the PDAC epigenome and histone acetylation in particular, with broad implications for microenvironmental regulation of gene expression and phenotype in neoplastic cells (MH Sherman, RT Yu, TW Tseng, et al., in prep.). Further, we found that inhibition of

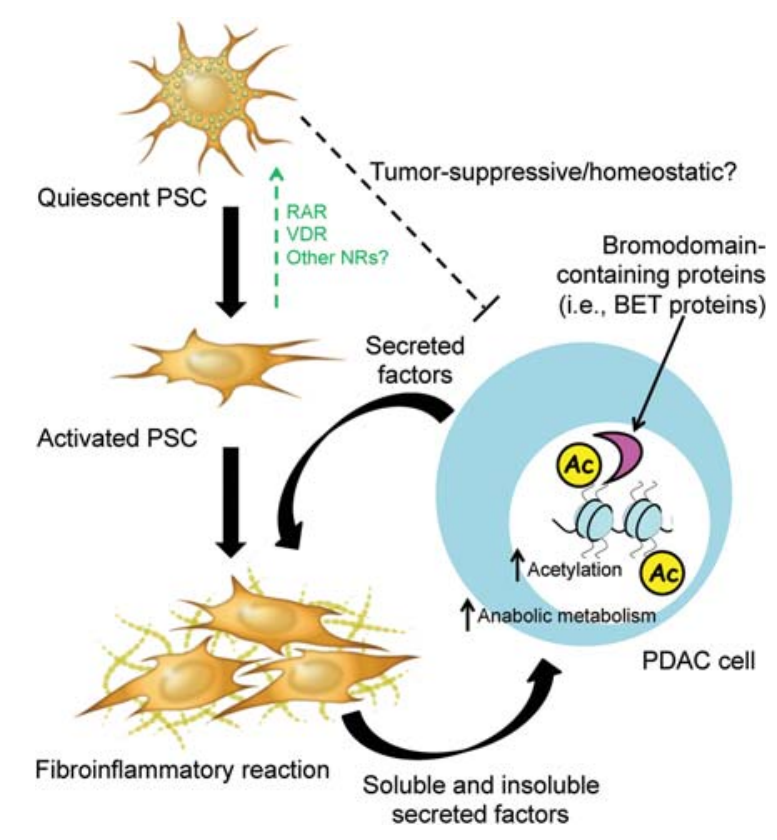

Figure 2. Model for reciprocal tumor-stroma interaction in pancreatic ductal adenocarcinoma (PDAC) between cancer cells and pancreatic stellate cells (PSCs), including proposed stromal or epithelial therapeutic targets. RAR, retinoic acid receptor; VDR, vitamin D receptor; NR, nuclear receptor. acetyllysine sensing by BET bromodomains reduced stroma-inducible changes in gene expression and suppressed tumor growth in vivo. The emerging concept of tissue-specific epigenomic regulation may have important implications in both physiology and disease. Microenvironmental regulation of epigenetic landscapes was recently demonstrated in distinct populations of tissuespecific macrophages (Gosselin et al. 2014; Lavin et al. 2014). These studies showed that soluble (and perhaps insoluble) cues in distinct macrophage niches shape enhancer repertoires to support tissue-specific gene expression patterns and macrophage functions. Additional studies in humans have demonstrated that tissue environments can directly modulate global DNA methylation patterns, particularly in enhancer regions, in normal differentiated cells (Lay et al. 2014). The extent to which local signals from the fibroinflammatory tumor microenvironment shape the pancreatic cancer epigenome, and the functional consequences of these effects, will be the subject of future investigation.

\section{THERAPEUTIC STRATEGIES TARGETING MICROENVIRONMENTAL SIGNALING NETWORKS}

Vitamin D analogs have been broadly implicated as anticancer agents. Epidemiological studies indicate a strong inverse correlation between vitamin D intake or plasma vitamin D levels and risk for developing multiple forms of human cancer (Ahonen et al. 2000; Feskanich et al. 2004; Gorham et al. 2005; Lappe et al. 2007), including pancreatic cancer (Skinner et al. 2006; Wolpin et al. 2012). Other studies, however, have concluded that high levels of dietary vitamin D intake increase pancreatic cancer risk (Waterhouse et al. 2015), and detailed studies of the role of vitamin D signaling in pancreatic cancer initiation and progression are needed. Previous studies investigating the therapeutic potential of vitamin $\mathrm{D}$ analogs in pancreatic cancer have considered direct effects of the active vitamin D metabolite 1,25-dihydroxyvitamin $\mathrm{D}_{3}$ (calcitriol) on cancer cell proliferation, differentiation, and apoptosis and have thus rationalized the use of vitamin D analogs as single-agent therapy in pancreatic cancer (Evans et al. 2002). Published work, in agreement with data from our group (Sherman et al. 2014), demonstrates minimal direct antitumor effect of vitamin D analogs in vivo. A recent phase II clinical trial, again using direct effects of vitamin D analogs on neoplastic cells as rationale, tested the safety and efficacy of calcitriol plus docetaxel, a second-line chemotherapeutic agent, in patients with nonresectable, incurable pancreatic cancer (Blanke et al. 2009). In this study, noncontinuous dosing was used, based on preclinical evidence that sporadic exposure was sufficient to induce growth inhibition of neoplastic cell lines. In addition, calcitriol and other vitamin D analogs have been of limited therapeutic utility because of dose-dependent hypercalcemia, which precludes administration of high and/or frequent doses to cancer patients. Nonetheless, time to progression improved in patients given combination therapy compared 
to docetaxel alone. Although efficacy was otherwise quite limited, our proposed use of calcipotriol, a potent and nonhypercalemic vitamin $\mathrm{D}$ analog, permits more frequent dosing, which may be required to effectively harness the therapeutic potential of VDR activation. Calcipotriol was recently shown to inhibit Wnt signaling in VDR-expressing PDAC cell lines (Arensman et al. 2015), suggesting another potential mechanism for antitumor activity of synthetic VDR agonism. Further, our work suggests a revised view of VDR activation in pancreatic cancer as a mechanism for signal-dependent transcriptional remodeling of the tumor-stroma, which significantly enhanced intratumoral gemcitabine concentration and efficacy. Although cancer cell-intrinsic resistance to current chemotherapies certainly remains a major obstacle, the VDR-mediated stromal reprogramming paradigm may be applicable in combination with novel therapies directed at neoplastic cells to improve chemotherapeutic efficacy in pancreatic cancer and potentially other stroma-rich malignancies.

Additional therapeutic strategies have emerged with molecular targets in the tumor microenvironment or in stroma-responsive networks in cancer cells. BET bromodomain inhibition has garnered excitement as a therapeutic strategy in hematologic malignancies and in solid tumors, and BET inhibitors hold promise in PDAC because of direct antitumor action on neoplastic cells (Garcia et al. 2015; Roy et al. 2015). Our recent work suggests therapeutic potential of BET inhibition in PDAC due to additional roles of the BET family in transducing microenvironmental cues in PDAC cells and raises the possibility that the antifibrotic action of BET inhibition in HSCs may extend to PSCs in the PDAC microenvironment. Combination therapeutic strategies that generate a treatment-permissive microenvironment hold much promise, as evidenced by current trials testing combinations of cytotoxic chemotherapy and microenvironmenttargeted agents such as PEGylated hyaluronidase (Provenzano et al. 2012; Jacobetz et al. 2013) to normalize the elevated pressure within the tumor microenvironment and relieve inhibition of intratumoral vasculature. Other agents are aimed at reducing immune-suppressive functions of stromal elements to overcome barriers to antitumor immunity, including strategies targeting tumorassociated macrophages (anti-CD40) (Beatty et al. 2011), vaccines to stimulate antitumor T-cell activation (Arensman et al. 2015; Le et al. 2015), or neutralizing antibodies against CXCL12/SDF-1, a stroma-derived chemokine that excludes T cells from the PDAC microenvironment (Feig et al. 2013). Increasing our understanding of the molecular mediators of tumor-stroma interaction will elucidate additional candidates to be targeted therapeutically.

\section{CONCLUSION AND FUTURE PERSPECTIVES}

Transcriptional and epigenetic regulators in the epithelial and stromal compartments are dysregulated during fibrosis and cancer progression, and it is critical to iden- tify the therapeutics that are selective for each pathogenic event. An improved understanding of these networks, and the interactions between these tissue components, may elucidate novel targets for therapeutic intervention that promotes differentiation of cancer cells or reintroduces homeostatic control to a fibroinflammatory, tumor-permissive microenvironment. Compelling results from the recent literature highlight the tumor-suppressive potential of microenvironmental components (Lee et al. 2014; Özdemir et al. 2014; Rhim et al. 2014), underscoring the need to dissect the molecular bases of tumor-stroma interactions and to develop therapies that aid in tipping the balance toward tumor-suppressive homeostasis. We predict that the homeostatic and metabolic control exerted by nuclear receptors and their ligands in development and disease will make these often-druggable transcription factors promising therapeutic targets in PDAC. Future work in our laboratory will aim to characterize the roles of nuclear receptor superfamily members in the PDAC tumor microenvironment and neoplastic compartment and to identify chromatin-modifying cofactors that may serve as additional targets for therapeutic intervention and clinical benefit. Further understanding in transcriptional and epigenetic control will vastly improve our understanding of how this cell is able to convert its phenotype in response to cues in its microenvironment.

\section{ACKNOWLEDGMENTS}

We thank L. Ong and C. Brondos for administrative assistance and Annette R. Atkins for proofreading and editing. R.M.E. is an Investigator of the Howard Hughes Medical Institute (HHMI) at the Salk Institute and March of Dimes Chair in Molecular and Developmental Biology and is supported by National Institutes of Health (NIH) grants (DK057978, HL088093, HL105278, and ES010337), a Stand Up to Cancer Dream Team Translational Cancer Research Grant, a Program of the Entertainment Industry Foundation (SU2C-AACR-DT0509), the Glenn Foundation for Medical Research, the Leona M. and Harry B. Helmsley Charitable Trust (2102PG-MED002), Ipsen/Biomeasure, California Institute for Regenerative Medicine, and The Ellison Medical Foundation.

\section{REFERENCES}

Abramovitch S, Dahan-Bachar L, Sharvit E, Weisman Y, Ben Tov A, Brazowski E, Reif S. 2011. Vitamin D inhibits proliferation and profibrotic marker expression in hepatic stellate cells and decreases thioacetamide-induced liver fibrosis in rats. Gut 60: 1728-1737.

Ahonen MH, Tenkanen L, Teppo L, Hakama M, Tuohimaa P. 2000. Prostate cancer risk and prediagnostic serum 25hydroxyvitamin D levels (Finland). Cancer Causes Control 11: $847-852$.

Apte MV, Haber PS, Applegate TL, Norton ID, McCaughan GW, Korsten MA, Pirola RC, Wilson JS. 1998. Periacinar stellate shaped cells in rat pancreas: Identification, isolation, and culture. Gut 43: 128-133.

Arensman MD, Nguyen P, Kershaw KM, Lay AR, Ostertag-Hill CA, Sherman MH, Downes M, Liddle C, Evans RM, Dawson 
DW. 2015. Calcipotriol targets LRP6 to inhibit Wnt signaling in pancreatic cancer. Mol Cancer Res 13: 1509-1519.

Bachem MG, Schneider E, Groß H, Weidenbach H, Schmid RM, Menke A, Siech M, Beger H, Grünert A, Adler G. 1998. Identification, culture, and characterization of pancreatic stellate cells in rats and humans. Gastroenterology 115: 421-432.

Bataller R, Brenner DA. 2005. Liver fibrosis. J Clin Inves 115: 209-218.

Beatty GL, Chiorean EG, Fishman MP, Saboury B, Teitelbaum UR, Sun W, Huhn RD, Song W, Li D, Sharp LL, et al. 2011. CD40 agonists alter tumor stroma and show efficacy against pancreatic carcinoma in mice and humans. Science 331: $1612-1616$.

Blanke CD, Beer TM, Todd K, Mori M, Stone M, Lopez C. 2009. Phase II study of calcitriol-enhanced docetaxel in patients with previously untreated metastatic or locally advanced pancreatic cancer. Invest New Drugs 27: 374-378.

Bläuer M, Sand J, Laukkarinen J. 2015. Physiological and clinically attainable concentrations of 1,25-dihydroxyvitamin $\mathrm{D}_{3}$ suppress proliferation and extracellular matrix protein expression in mouse pancreatic stellate cells. Pancreatology 15: $366-371$.

Bookout AL, Jeong Y, Downes M, Yu RT, Evans RM, Mangelsdorf DJ. 2006. Anatomical profiling of nuclear receptor expression reveals a hierarchical transcriptional network. Cell 126: 789-799.

Bouillon R, Carmeliet G, Verlinden L, van Etten E, Verstuyf A, Luderer HF, Lieben L, Mathieu C, Demay M. 2008. Vitamin $\mathrm{D}$ and human health: Lessons from vitamin D receptor null mice. Endocr Rev 29: 726-776.

Breitkopf K, Godoy P, Ciuclan L, Singer MV, Dooley S. 2006. TGF- $\beta$ /Smad signaling in the injured liver. $Z$ Gastroenterol 44: $57-66$.

Buchholz M, Kestler HA, Holzmann K, Ellenrieder V, Schneiderhan W, Siech M, Adler G, Bachem MG, Gress TM. 2005. Transcriptome analysis of human hepatic and pancreatic stellate cells: Organ-specific variations of a common transcriptional phenotype. J Mol Med 83: 795-805.

Ding N, Yu RT, Subramaniam N, Sherman MH, Wilson C, Rao R, Leblanc M, Coulter S, He M, Scott C, et al. 2013. A vitamin $\mathrm{D}$ receptor/SMAD genomic circuit gates hepatic fibrotic response. Cell 153: 601-613.

Ding N, Hah N, Yu RT, Sherman MH, Benner C, Leblanc M, He M, Liddle C, Downes M, Evans RM. 2015. BRD4 is a novel therapeutic target for liver fibrosis. Proc Natl Acad Sci 112: 15713-15718.

Ene-Obong A, Clear AJ, Watt J, Wang J, Fatah R, Riches JC, Marshall JF, Chin-Aleong J, Chelala C, Gribben JG, et al. 2013. Activated pancreatic stellate cells sequester CD8 ${ }^{+}$ $\mathrm{T}$ cells to reduce their infiltration of the juxtatumoral compartment of pancreatic ductal adenocarcinoma. Gastroenterology 145: 1121-1132.

Evans RM, Mangelsdorf DJ. 2014. Nuclear receptors, RXR, and the big bang. Cell 157: 255-266.

Evans TR, Colston KW, Lofts FJ, Cunningham D, Anthoney DA, Gogas H, de Bono JS, Hamberg KJ, Skov T, Mansi JL. 2002. A phase II trial of the vitamin D analogue Seocalcitol (EB1089) in patients with inoperable pancreatic cancer. $\mathrm{Br}$ $J$ Cancer 86: 680-685.

Feig C, Jones JO, Kraman M, Wells RJB, Deonarine A, Chan DS, Connell CM, Roberts EW, Zhao Q, Caballero OL, et al. 2013. Targeting CXCL12 from FAP-expressing carcinomaassociated fibroblasts synergizes with anti-PD-L1 immunotherapy in pancreatic cancer. Proc Natl Acad Sci 110: $20212-$ 20217.

Feskanich D, Ma J, Fuchs CS, Kirkner GJ, Hankinson SE, Hollis BW, Giovannucci EL. 2004. Plasma vitamin D metabolites and risk of colorectal cancer in women. Cancer Epidemiol Biomarkers Prev 13: 1502-1508.

Filippakopoulos P, Qi J, Picaud S, Shen Y, Smith WB, Fedorov O, Morse EM, Keates T, Hickman TT, Felletar I, et al. 2010.
Selective inhibition of BET bromodomains. Nature 468: 1067-1073.

Friedman SL. 2000. Molecular regulation of hepatic fibrosis, an integrated cellular response to tissue injury. J Biol Chem 275: $2247-2250$

Friedman SL. 2008. Hepatic stellate cells: Protean, multifunctional, and enigmatic cells of the liver. Physiol Rev 88: $125-$ 172.

Froeling FE, Feig C, Chelala C, Dobson R, Mein CE, Tuveson DA, Clevers H, Hart IR, Kocher HM. 2011. Retinoic acidinduced pancreatic stellate cell quiescence reduces paracrine Wnt- $\beta$-catenin signaling to slow tumor progression. Gastroenterology 141: 1486-1497, 1497.e1-1497.e14.

Garcia PL, Miller AL, Kreitzburg KM, Council LN, Gamblin TL, Christein JD, Heslin MJ, Arnoletti JP, Richardson JH, Chen D, et al. 2015. The BET bromodomain inhibitor JQ1 suppresses growth of pancreatic ductal adenocarcinoma in patient-derived xenograft models. Oncogene doi: 10.1038/ onc. 2015.126

Gascon-Barré M, Demers C, Mirshahi A, Néron S, Zalzal S, Nanci A. 2003. The normal liver harbors the vitamin D nuclear receptor in nonparenchymal and biliary epithelial cells. Hepatology 37: 1034-1042.

Gorham ED, Garland CF, Garland FC, Grant WB, Mohr SB, Lipkin M, Newmark HL, Giovannucci E, Wei M, Holick MF. 2005. Vitamin D and prevention of colorectal cancer. J Steroid Biochem Mol Biol 97: 179-194.

Gosselin D, Link VM, Romanoski CE, Fonseca GJ, Eichenfield DZ, Spann NJ, Stender JD, Chun HB, Garner H, Geissmann F, et al. 2014. Environment drives selection and function of enhancers controlling tissue-specific macrophage identities. Cell 159: 1327-1340.

Han S, Li T, Ellis E, Strom S, Chiang JY. 2010. A novel bile acid-activated vitamin D receptor signaling in human hepatocytes. Mol Endocrinol 24: 1151-1164.

Hernandez-Gea V, Friedman SL. 2011. Pathogenesis of liver fibrosis. Annu Rev Pathol 6: 425-456.

Hingorani SR, Wang L, Multani AS, Combs C, Deramaudt TB, Hruban RH, Rustgi AK, Chang S, Tuveson DA. 2005. Trp53R172H and KrasG12D cooperate to promote chromosomal instability and widely metastatic pancreatic ductal adenocarcinoma in mice. Cancer Cell 7: 469-483.

Inagaki Y, Okazaki I. 2007. Emerging insights into Transforming growth factor $\beta$ Smad signal in hepatic fibrogenesis. Gut 56: $284-292$.

Jacobetz MA, Chan DS, Neesse A, Bapiro TE, Cook N, Frese KK, Feig C, Nakagawa T, Caldwell ME, Zecchini HI, et al. 2013. Hyaluronan impairs vascular function and drug delivery in a mouse model of pancreatic cancer. Gut 62: $112-120$.

Klemm F, Joyce JA. 2015. Microenvironmental regulation of therapeutic response in cancer. Trends Cell Biol 25: 198-213.

Lappe JM, Travers-Gustafson D, Davies KM, Recker RR, Heaney RP. 2007. Vitamin D and calcium supplementation reduces cancer risk: Results of a randomized trial. Am J Clin Nutr 85: $1586-1591$.

Lavin Y, Winter D, Blecher-Gonen R, David E, Keren-Shaul H, Merad M, Jung S, Amit I. 2014. Tissue-resident macrophage enhancer landscapes are shaped by the local microenvironment. Cell 159: 1312-1326.

Lay FD, Triche TJ Jr, Tsai YC, Su SF, Martin SE, Daneshmand S, Skinner EC, Liang G, Chihara Y, Jones PA. 2014. Reprogramming of the human intestinal epigenome by surgical tissue transposition. Genome Res 24: 545-553.

Le DT, Wang-Gillam A, Picozzi V, Greten TF, Crocenzi T, Springett G, Morse M, Zeh H, Cohen D, Fine RL, et al. 2015. Safety and survival with GVAX pancreas prime and Listeria monocytogenes-expressing mesothelin (CRS-207) boost vaccines for metastatic pancreatic cancer. J Clin Oncol 33: $1325-1333$.

Lee TI, Young RA. 2013. Transcriptional regulation and its misregulation in disease. Cell 152: 1237-1251. 
Lee JJ, Perera RM, Wang H, Wu DC, Liu XS, Han S, Fitamant J, Jones PD, Ghanta KS, Kawano S, et al. 2014. Stromal response to Hedgehog signaling restrains pancreatic cancer progression. Proc Natl Acad Sci 111: E3091-E3100.

Mangelsdorf DJ, Thummel C, Beato M, Herrlich P, Schütz G, Umesono K, Blumberg B, Kastner P, Mark M, Chambon P, et al. 1995. The nuclear receptor superfamily: The second decade. Cell 83: 835-839.

Mann J, Mann DA. 2009. Transcriptional regulation of hepatic stellate cells. Adv Drug Deliv Rev 61: 497-512.

Melo SA, Luecke LB, Kahlert C, Fernandez AF, Gammon ST, Kaye J, LeBleu VS, Mittendorf EA, Weitz J, Rahbari N, et al. 2015. Glypican-1 identifies cancer exosomes and detects early pancreatic cancer. Nature 523: $177-182$.

Olive KP, Jacobetz MA, Davidson CJ, Gopinathan A, McIntyre D, Honess D, Madhu B, Goldgraben MA, Caldwell ME, Allard D, et al. 2009. Inhibition of Hedgehog signaling enhances delivery of chemotherapy in a mouse model of pancreatic cancer. Science 324: 1457-1461.

Özdemir BC, Pentcheva-Hoang T, Carstens JL, Zheng X, Wu CC, Simpson TR, Laklai H, Sugimoto H, Kahlert C, Novitskiy SV, et al. 2014. Depletion of carcinoma-associated fibroblasts and fibrosis induces immunosuppression and accelerates pancreas cancer with reduced survival. Cancer Cell 25: $719-734$.

Provenzano PP, Cuevas C, Chang AE, Goel VK, Von Hoff DD, Hingorani SR. 2012. Enzymatic targeting of the stroma ablates physical barriers to treatment of pancreatic ductal adenocarcinoma. Cancer Cell 21: 418-429.

Rhim AD, Oberstein PE, Thomas DH, Mirek ET, Palermo CF, Sastra SA, Dekleva EN, Saunders T, Becerra CP, Tattersall IW, et al. 2014. Stromal elements act to restrain, rather than support, pancreatic ductal adenocarcinoma. Cancer Cell 25: $735-747$.

Riopel MM, Li J, Liu S, Leask A, Wang R. 2013. $\beta 1$ integrinextracellular matrix interactions are essential for maintaining exocrine pancreas architecture and function. Lab Invest 93: 31-40.
Roy N, Malik S, Villanueva KE, Urano A, Lu X, Von Figura G, Seeley ES, Dawson DW, Collisson EA, Hebrok M. 2015. Brg1 promotes both tumor-suppressive and oncogenic activities at distinct stages of pancreatic cancer formation. Genes Dev 29: 658-671.

Sherman MH, Yu RT, Engle DD, Ding N, Atkins AR, Tiriac H, Collisson EA, Connor F, Van Dyke T, Kozlov S, et al. 2014 Vitamin D receptor-mediated stromal reprogramming suppresses pancreatitis and enhances pancreatic cancer therapy. Cell 159: 80-93.

Skinner HG, Michaud DS, Giovannucci E, Willett WC, Colditz GA, Fuchs CS. 2006. Vitamin D intake and the risk for pancreatic cancer in two cohort studies. Cancer Epidemiol Biomarkers Prev 15: 1688-1695.

Vonlaufen A, Joshi S, Qu C, Phillips PA, Xu Z, Parker NR, Toi CS, Pirola RC, Wilson JS, Goldstein D, et al. 2008. Pancreatic stellate cells: Partners in crime with pancreatic cancer cells. Cancer Res 68: 2085-2093.

Wake K. 1971. "Sternzellen" in the liver: Perisinusoidal cells with special reference to storage of vitamin A. Am J Anat 132: 429-462.

Watari N, Hotta Y, Mabuchi Y. 1982. Morphological studies on a vitamin A-storing cell and its complex with macrophage observed in mouse pancreatic tissues following excess vitamin A administration. Okajimas Folia Anat Jpn 58: $837-858$

Waterhouse M, Risch HA, Bosetti C, Anderson KE, Petersen GM, Bamlet WR, Cotterchio M, Cleary SP, Ibiebele TI, La Vecchia C, et al. 2015. Vitamin D and pancreatic cancer: A pooled analysis from the Pancreatic Cancer Case-Control Consortium. Ann Oncol 26: 1776-1783.

Wehr AY, Furth EE, Sangar V, Blair IA, Yu KH. 2011. Analysis of the human pancreatic stellate cell secreted proteome. Pancreas 40: $557-566$.

Wolpin BM, Ng K, Bao Y, Kraft P, Stampfer MJ, Michaud DS, Ma J, Buring JE, Sesso HD, Lee IM, et al. 2012. Plasma 25hydroxyvitamin D and risk of pancreatic cancer. Cancer Epidemiol Biomarkers Prev 21: 82-91. 


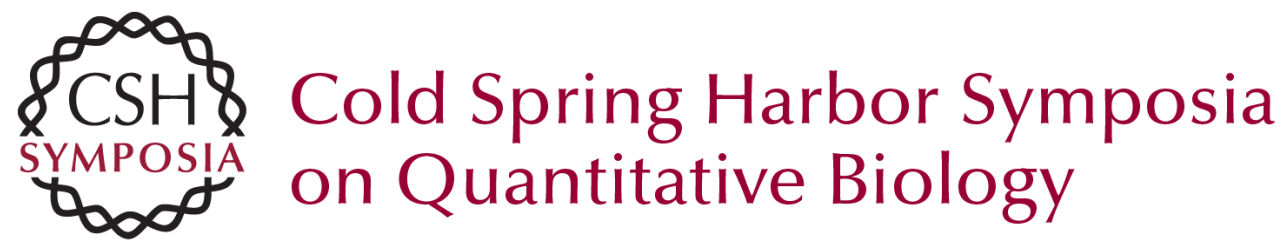

\section{Targeting Transcriptional and Epigenetic Reprogramming in Stromal Cells in Fibrosis and Cancer}

Nasun Hah, Mara H. Sherman, Ruth T. Yu, et al.

Cold Spring Harb Symp Quant Biol 2015 80: 249-255 originally published online January 22, 2016

Access the most recent version at doi:10.1101/sqb.2015.80.027185

References This article cites 57 articles, 19 of which can be accessed free at: http://symposium.cshlp.org/content/80/249.full.html\#ref-list-1

\section{License}

Email Alerting Receive free email alerts when new articles cite this article - sign up in Service the box at the top right corner of the article or click here. 